\title{
Examining temporal alterations in Social Anxiety Disorder and Posttraumatic Stress Disorder: The relation between autobiographical memory, future goals, and current self-views
}

\author{
Julie Krans $^{\mathrm{a}, *}$, Manon Peeters ${ }^{\mathrm{b}}$, Gérard Näring ${ }^{\mathrm{c}}$, Adam D. Brown ${ }^{\mathrm{d}, \mathrm{e}}$, June de Bree ${ }^{\mathrm{c}}$, Agnes van Minnen ${ }^{\mathrm{b}, \mathrm{c}, 1}$ \\ ${ }^{a}$ Behavior, Health \& Psychopathology, KU Leuven, Tiensestraat 102, 3000 Leuven, Belgium \\ ${ }^{\mathrm{b}}$ Centre for Anxiety Disorders Overwaal, Institution for Integrated Mental Health Care Pro Persona, Tarweweg 2, Postbus 31253, 6503 CG, Nijmegen, The Netherlands, \\ ${ }^{c}$ Behavioural Science Institute, Radboud University Nijmegen, P.O. Box 9104, 6500 HE, Nijmegen, The Netherlands \\ ${ }^{\mathrm{d}}$ Department of Psychology, Sarah Lawrence College, 1 Mead Way, Bronxville, NY 10708, United States \\ ${ }^{\mathrm{e}}$ Department of Psychiatry, New York University School of Medicine, 1 Park Avenue New York, NY 10016, United States
}

\section{A R T I C L E I N F O}

Keywords:

Autobiographical memory

Self-views

Social anxiety disorder

PTSD

Future thinking

\begin{abstract}
A B S T R A C T
The self is a multi-faceted and temporally dynamic construct reflecting representations and beliefs about identity in the past, present, and future. Clinical studies have shown that individuals with Posttraumatic Stress Disorder (PTSD) and Social Anxiety Disorder (SAD) exhibit alterations in self-related processing but these studies have focused primarily on memory. Few studies in PTSD and SAD have examined self-related processing for the present and future, and no studies have directly compared these processes across these two disorders. Individuals diagnosed with PTSD $(n=21)$, SAD $(n=21)$, and healthy controls $(n=21)$ completed cognitive tasks related to the past, present, and future. Disorder congruent temporal alterations were found across both disorders. Further, regression analyses revealed that trauma-related memories were significantly predicted by future goals related to the trauma, whereas social anxiety-related recall was predicted by current socially anxious self-views. Thus, although self-related processing may be common in PTSD and SAD, those aspects of the self most strongly associated with disorder-congruent recall differ by disorder. Self-alterations may be modifiable and developing a better understanding of past, present, and future self-processing might aid in the development of interventions that target these process.
\end{abstract}

\section{Introduction}

A sense of self has been conceptualized as a set of mental processes that supports individuality and coherence (Damasio, 2003; Harré, 1998). As famously characterized by James (1890) and expanded upon by many others (for a review see Prebble, Addis, \& Tippett, 2013) the self is, in part, comprised of knowledge, beliefs, and representations that extend beyond the present, and how one constructs a sense of self is associated with well-being across the lifespan (Fivush, Haden, \& Reese, 2006; McAdams, 1993; Ross \& Wilson, 2003).

Recently, Prebble et al. (2013) posited a Sense of Self framework (2013) in which they delineate the sense of self along two dimensions: the subjective (consciousness) versus objective (self-views) and the pre- sent versus temporally extended self (past, present, and future). Moreover, Stopa (2009) has posited that the self can be studied along three dimensions: 'content' (information and representations about the self), 'process' (the allocation of self-related information), and 'structure' (how the self is organized). Central to the characterization of anxiety and stress-related disorders is the presence of maladaptive beliefs about one's self in the past, present, and future in relation to feared stimuli, and treatments often focus on the modification of such self-beliefs (e.g. Beck, 1976). Therefore, in line with the frameworks of both Prebble et al. (2013) and Stopa (2009), an understanding of alterations in the content of the extended sense of self may play an important role in the pathogenesis of anxiety and stress-related disorders.

\footnotetext{
* Corresponding author.

Email addresses: julie.krans@kuleuven.be, j.krans@psych.ru.nl (J. Krans); m.peeters01@propersona.nl (M. Peeters); g.naring@bsi.ru.nl (G. Näring); abrown@sarahlawrence.edu (A.D. Brown); junedebree@gmail.com (J. de Bree); a.van.minnen@propersona.nl, a.vanminnen@bsi.ru.nl, vanminnen@psytrec.com (A.van Minnen)

1 Agnes van Minnen is presently affiliated with PSYTREC, Prof. Bronkhorstlaan 2, 3723 MB Bilthoven, The Netherlands.
} 
In fact, cognitive models of both Posttraumatic Stress Disorder (PTSD) and Social Anxiety Disorder (SAD) emphasize the role of the self in the trajectory of these disorders. For example, cognitive models of PTSD suggest that maladaptive appraisals of one's past, present and future increase one's vulnerability to PTSD onset and the maintenance of symptoms (e.g. Ehlers \& Clark, 2000). In particular, such models posit that maladaptive self-appraisals in line with PTSD symptomatology increase the accessibility of trauma-related memories and lead to the selective retrieval of memories associated with trauma in a way that in turn reinforces one's maladaptive self-views. Similarly, studies using the Centrality of Event Scale, a self-report measure assessing the extent to which people believe the trauma is central to their life-story, is positively correlated with PTSD symptom severity (e.g., Berntsen \& Rubin, 2006, 2007). Rubin, Berntsen, and Bohni (2008) have theorized that the more a person uses the trauma as a lens through which they view the past, present, and future, the more likely they will retrieve memories associated with the trauma.

Cognitive models of SAD have similarly emphasized the role of the self (Gregory, Peters, \& Rapee, 2017). For example, models of SAD propose that individuals with SAD construct maladaptive internal representations based on their feared expectations of an (imagined) audience (Clark \& Wells, 1995; Heimberg, Brozovich, \& Rapee, 2010; Rapee \& Heimberg, 1997). Such models propose that it is these biased self-representations that impair a person with SAD to integrate feedback from others in social situations, which in turn, motivates socially-anxious behaviors and processes and prevents them from updating maladaptive self-views. Related cognitive models of SAD have also emphasized self-discrepancies between actual, other, and ought selves in SAD (Hofmann, 2007), as well as a core set of fears related to the self such as flaws in one's appearance, personality, and social abilities (Moscovitch, 2009). Moreover, these self-related processes are also thought to impact on selective retrieval of autobiographical memories related to social anxiety (e.g., of negative social evaluation; Clark \& Wells, 1995; Rapee \& Heimberg, 1997).

In sum, disorder-congruent autobiographical recall appears to be a central process in PTSD and SAD. Yet, less is known about the self-related processing that supports this selective recall. Overall, although theoretical and experimental studies of the self have been conducted in PTSD and SAD, there remains a lack of research identifying shared mechanisms and risk factors underlying autobiographical recall in both PTSD and SAD. More broadly, initiatives such as the National Institute of Mental Health's (NIMH) Research Domain Criteria (RDOC, Cuthbert \& Insel, 2013) emphasize the importance of identifying neurobiological, affective, and cognitive processes that underlie anxiety and stress-related psychopathology. In addition, although treatments such as CBT have been shown to be effective for PTSD and SAD, a significant minority of individuals diagnosed with these disorders do not benefit from current interventions (e.g. Craske \& Mystkowski 2006; Mayo-Wilson et al., 2014; Rapee, Gaston, \& Abbott, 2009). As such, identifying maladaptive self-related processes in autobiographical recall may help to better inform or increase the efficacy of current therapeutic approaches (e.g. Kazdin, 2007).

Cognitive models of autobiographical memory offer a useful framework for examining how individuals with PTSD and SAD view themselves in the past, present, and future. Autobiographical memories represent a subgroup of long-term episodic and semantic memories that comprise events deemed central to one's life story. In particular, Conway and colleagues (Conway, 2005; Conway \& Pleydell-Pearce, 2000) created the Self-Memory-System (SMS) model that emphasizes the highly interrelated constructs of autobiographical memory and the self. In this model there is strong congruency between the memory and the self. That is, one's self, including attitudes and beliefs, may change to be consistent with autobiographical knowledge. In addition, the acces- sibility and content of autobiographical memories may be constructed to be consistent with the current and anticipated future needs of the self. Furthermore, Conway and Pleydell-Pearce (2000) propose that autobiographical memories are retrieved within the context of a self-memory-system (SMS) to support the 'working self', which involves active representations of one's current self-views and future goals. Conway (2005) argues that the working self may inhibit or facilitate the recall of autobiographical memories that are discrepant or may threaten held views of the self.

Therefore, according to the SMS, maladaptive beliefs about one's self may increase the accessibility of memories that support the fears of that individual (e.g. in SAD: times in the past when they felt rejected by others; in PTSD: the traumatic event in the past). Empirical research with PTSD patients and socially anxious students appears to support the SMS model in that when these individuals are asked to recall autobiographical memories, they are more likely than controls to generate content in line with their disorder or fears (e.g. trauma-related memories in PTSD; memories of social evaluation in social anxiety; Sutherland \& Bryant, 2005, 2008; Krans, De Bree, \& Bryant, 2013). This has not been tested yet for SAD patients, however.

Importantly, the SMS suggests that current self-views and future goals also contribute to self-identity, and in turn, shape the content and accessibility of autobiographical memory. Although current self-appraisals have been studied in SAD and PTSD (e.g. Ehlers \& Clark, 2000; Hofmann, 2007; Ng, Abbott, \& Hunt, 2014), less is known about how potential biases for current and future self-processes relate to memory within these disorders. For example, in the study by Sutherland and Bryant (2008) traumatized participants with or without PTSD were asked to complete an autobiographical memory test and an assessment of self-discrepancy (i.e., the discrepancy between one's current and ideal or ought view of the self). They found that those with PTSD were more likely to demonstrate a discrepancy between their actual self and ideal self. Additionally, there was a positive correlation between the strength of this discrepancy and the number of trauma memories generated during the autobiographical memory test, suggesting that, in line with the SMS model, current self-views and memories are a related process.

Similarly, individuals with SAD have shown alterations in self-views. A recent synthesis of these studies has shown that alterations in self-views have been studied using a variety of methods and such maladaptive self-views appear to increase levels of anxiety among socially-anxious individuals (for a review, see: $\mathrm{Ng}$ et al., 2014). In one study on autobiographical memory recall, Krans et al. (2013) found that discrepancies between one's current self and ideal self were higher in social anxious university students and these discrepancies were associated with congruent autobiographical memory recall, in which students high in social anxiety were more likely to recall memories associated with feared social situations.

With regard to the extended self in the future, the SMS model would predict that future goals would be constructed in line with one's current symptomatology. To date, few studies have examined whether future goals are altered in PTSD and SA. Sutherland and Bryant (2005) administered a future goals task and found that those with PTSD were more likely to generate goals that incorporated trauma than traumatized non-PTSD controls. In a similar line of research, Krans et al. (2013) found that university students high in social anxiety were more likely to identify goals reflecting socially-feared situations. This has not been verified in clinical SAD patients yet.

Taken together, disorder-congruent autobiographical recall appears to be a problematic and central mechanism according to cognitive models of PTSD but also SAD. Moreover, current evidence-based treatments are effective but a significant minority of patients does not benefit. Therefore it is important to study factors that influence core mecha- 
nisms such as autobiographical memory, in order to strengthen interventions. The main aims of this study were therefore (1) to assess whether the disorder-congruent bias found in autobiographical memory can be observed in other temporal frames (current self-views and future goals) for PTSD and SAD, (2), to compare whether these biases emerge to a similar extent across both PTSD and SAD, and (3) to determine which components (present and future) are most strongly associated with selective autobiographical recall of trauma or situations of (negatively interpreted) social evaluation. The SMS model would posit that those with PTSD and SAD exhibit biases that reflect their symptomatology across the past, present and future self. Furthermore, discrepancies between current self and desired states of the self would be expected to increase the accessibility of congruent information from memory because this is functional for problem solving in order to reduce these discrepancies (Conway, 2005; Higgins, Shah, \& Friedman, 1997). Predictions were based on the SMS model, cognitive models of PTSD (e.g., Berntsen \& Rubin, 2006, 2007; Ehlers \& Clark, 2000; Rubin et al., 2008) and SAD (Clark \& Wells, 1995; Gregory et al., 2017; Heimberg et al., 2010; Hofmann, 2007; Moscovitch, 2009; Rapee \& Heimberg, 1997) and the studies of Sutherland and Bryant $(2005,2008)$ and Krans et al. (2013) on the relations between self-processing and autobiographical recall in PTSD and socially anxious students, respectively.

In regards to the first aim, we expected that the PTSD group would generate more trauma-related memories, trauma-related future goals, and trauma-related current self-views than the SAD group and the healthy controls. It was also predicted that the SAD group would generate more social anxiety-related memories, more social anxiety-related future goals, and social anxiety-related current self-views compared to the PTSD group and healthy controls. In regards to the second aim, it was expected that all selective temporal biases (recall, current self-views, and future goals) would be present to a similar extent in PTSD and SAD as we had no reasons to assume otherwise, but more so than in a healthy control group. We furthermore expected that self-discrepancy would be higher in both clinical groups than in the healthy control group. In terms of the third goal, it was expected that congruent current self-views and self-discrepancies, as well as congruent future goals would predict trauma-related and social anxiety-related autobiographical recall over and above psychopathological symptoms (modeled after Sutherland \& Bryant, 2005, 2008; Krans et al., 2013).

\section{Method}

This study was approved by the Dutch medical-ethical committee (CCMO registration number 2010/463).

\subsection{Participants}

An a priori sample size calculation was performed with $\mathrm{G}^{*}$ power for $F$-tests for one-way ANOVAs with three groups. Effect size was calculated from the expected variance according to the average partial eta $^{2}$ reported in Sutherland and Bryant (2008), resulting in an estimated $f=0.52$. Alpha error probability was set to 0.05 , with a corresponding power of 0.95 . The total sample size needed for significant between-subject effects was estimated at 63 (21 participants per group). Participants were tested until this sample size was reached. Clinical participants were recruited at the Pro Persona Centre for Anxiety Disorders. Axis-I psychopathology was assessed with the Mini International Neuropsychiatric Interview (MINI; Overbeek, Schruers, \& Griez, 1997, 1999). Participants in the PTSD group were required to have a primary diagnosis of PTSD in the absence of comorbid SAD, a current psychotic episode, or current substance abuse. Participants in the SAD group were required to have a primary diagnosis of SAD in the absence of comorbid PTSD, a current psychotic episode, or current sub- stance abuse. The primary diagnosis was defined as the most interfering diagnosis. Participants for the healthy control group were recruited by advertisements in various public venues (e.g., commercial centers, university campuses, sports clubs) and social media. They were not eligible if they met criteria for any Axis I diagnosis. Eighty-two participants responded to the study announcement. Of those that expressed interest in participating in the study, 19 were excluded from analysis for the following reasons: 17 potential controls could not be matched on demographic variables with those with PTSD and SAD, one potential control participant fulfilled the MINI criteria for social anxiety disorder, and one PTSD patient did not complete multiple questionnaires. The final dataset contained 63 participants; PTSD: $N=21$ ( $n=20$ female), SAD: $N=21$ ( $n=9$ female), and healthy controls: $\mathrm{N}=21(n=10 \mathrm{fe}-$ males).

\subsection{Measures}

\subsubsection{Clinical symptoms}

The Posttraumatic Symptoms Scale-Self Report (PSS-SR; Foa, Riggs, Dancu, \& Rothbaum, 1993) was used to assess symptoms of PTSD. This questionnaire contains 17 items, which are rated on a 0-3 Likert scale (total range 0-51) assessing the frequency and degree of PTSD symptoms with subscales for re-experiencing (5 items, 0-15), avoidance (7 items, range 0-21), and arousal (5 items, range 0-15). The PSS-SR has satisfactory validity and high reliability (Foa et al., 1993). Social anxiety was measured with the Liebowitz Social Anxiety Scale (LSAS; Liebowitz, 1987). This questionnaire contains 24 statements for which both the degree of anxiety (range 0-72) and avoidance (range 0-72) are rated on a 0-3 scale (total score range 0-144). The LSAS is sufficiently reliable and valid for the measurement of social anxiety (Heimberg et al., 1999). As depressive symptoms are common in individuals suffering from psychological disorders and especially PTSD, we included the Beck, Steer, \& Brown, 1996), so we could control for depressive symptoms in the regression analyses. The BDI-II contains 21 items and participants select the most appropriate statement per item (scores ranging from 0 to 3 ; total score range 0-63). The BDI-II is a widely used reliable and valid measure of depression (Dozois, Dobson, \& Ahnberg, 1998).

\subsubsection{Autobiographical memory task (AMT)}

The AMT (Williams \& Broadbent, 1986) was administered to assess selective autobiographical recall in response to cue words. The experimenter presented participants with five negative cue words (hurt, tense, angry, fear, and stress) and five positive cue words (happy, brave, safe, love, and special), based on Sutherland \& Bryant (2008), each printed on a separate card. The presenter explained that the participant was to recall a specific autobiographical memory in response to each cue word (i.e., standard AMT instructions). The experimenter first gave an own example in response to the word "nice". Then, two practice trials (with the words "egg" and "chocolate") were administered where the experimenter could provide feedback, and the participant could ask questions for clarification. The cue words were then presented in pseudo-random order with the restriction that cue valence was alternated in consecutive trials. Responses were audio-recorded and transcribed for coding purposes.

\subsubsection{Self-defining memories}

Participants were asked by the experimenter to recall five specific self-defining memories (Emmons, 1986). The instruction (based on Sutherland \& Bryant, 2005) for each memory was to recall a memory about their life that they remembered very vividly, that felt important to them, that helped them understand who they are as a person, that could be a memory they would tell another person if they wanted that 
person to understand them on a more fundamental level, that could be positive or negative as long as it led to strong feelings, that they had thought about many times and that should be familiar to them as a photo that they have looked at often or a song that they knew by heart. Participants were asked to describe the memories out loud to the experimenter and they could take as much time as needed. Responses were audio-recorded and transcribed for coding purposes.

\subsubsection{Future goals}

Future goals were collected by asking participants to write down 15 goals that represented 'the things that are most important for you to achieve at this time' (Emmons, 1986; Krans et al., 2013; Sutherland \& Bryant, 2005).

\subsubsection{Self-views}

The Twenty-Statements-Test (TST; Kuhn \& McPartland, 1954; Horton, Moulin, \& Conway, 2009) was used to collect information on participants' current self-views. Participants were asked to complete 20 sentences starting with I am... in response to the question 'How would you describe yourself?'. These responses reflected verbal descriptions of current self-views.

\subsubsection{Self-discrepancy}

Self-discrepancy was measured with a computerized version of the Self-Strength Guide (Higgins et al., 1997; Holmes, Lang, \& Shah, 2009). Participants wrote down six personality characteristics that they would ideally like to possess (representing the Ideal self) and six characteristics that they felt they should possess (representing the Ought self), and rated the extent that they found these characteristics important on a Likert scale from 1 (a little) to 4 (extremely). Participants then rated on a similar Likert scale the extent to which they felt they already possessed each characteristic (representing the Actual self). For each characteristic, the absolute difference with the Actual self rating was calculated $(0-3)$. Two sum scores of these differences represented the Ideal and Ought self-discrepancies (range 0-18).

\subsection{Procedure}

Participants were tested individually in a quiet therapy room. All measures were presented on a PC using Inquisit experimental software (version 4.0.9.0), with the exception of the AMT and self-defining memories, which were administered in person by the experimenter (MP). Participants were first presented with a brief demographic questionnaire. Then the BDI-II, LSAS, and PSS-SR were administered. Next, the AMT, self-defining memories, goals, and self-views were assessed in randomized order to prevent their responses systematically influencing each other. After that, measures of self-esteem, history of childhood abuse, and tonic immobility were administered for purposes beyond the current study (not included in the analyses). Finally participants were debriefed and thanked for their participation.

\section{Results}

\subsection{Statistical approach}

Levene's tests indicated unequal error variances in some of the analyses. However, apart from a few exceptions (reported in footnotes), ANOVAs resulted in the same pattern of results as non-parametric analyses and therefore only the ANOVAs are reported. For $t$-tests, corrected values are reported in case of violation of the assumption of equal variances. Means and standard deviations for all measures are re- ported in Table 1. Cohen's $d$ is reported as the effect size for significant findings in the experimental analyses. Effect sizes of 0.20 are interpreted as small, 0.50 as medium, and 0.80 as large (Cohen, 1988).

\subsection{Coding ${ }^{2}$ and inter-rater reliability}

The content of responses on the AMT, self-defining memories, current goals, and self-views were coded into the following categories: trauma-related, social anxiety-related, or neither. Categories were considered mutually exclusive (i.e., no response was coded into more than one category). Coding was done blind to group by two independent raters for each response. Disagreements were resolved through discussion. In case the two independent raters could not come to an agreement, a third independent rater (also one of the authors) would make the final decision. For each participant, the number of memories on the AMT, self-defining memories, future goals, and current self-views were summed per category (trauma-related, social anxiety-related, and neither). Examples of responses coded into each category can be found in Table 2. The range of the inter-rater agreement (к) was 0.63-0.79 (see Table 3). These kappas are not high compared to earlier studies (Krans et al., 2013; Sutherland \& Bryant, 2005, 2008). However, different from these earlier studies, the current study required coding into two different anxiety-related categories (trauma-related and social anxiety-related) instead of one, which made the coding more difficult and this likely impacted the kappas. Nevertheless, according to the standards described by Landis and Koch (1977) our inter-rater agreement can be considered substantial, and therefore we considered it appropriate to continue with the analyses.

\subsection{Demographic variables}

There was a marginally significant difference in age between the three groups, $F(2,60)=2.95, p=0.06$. The PTSD group was significantly older on average than the SAD group and the healthy control group, both $p<0.05$. There was no significant difference in age between the SAD group and the healthy control group, $p=0.93$. The PTSD group contained 21 women and 1 man, whereas sex was more equally distributed in the SAD group ( 9 women and 12 men) and healthy control group (10 women and 11 men), $\chi^{2}(2)=14.94$, $p=0.001$. There was also a significant overall group difference in level of education, $F(2,60)=3.33, p=0.04$. The PTSD group had significantly lower levels of education than the healthy control group, $p=0.01$. The SAD group did not differ significantly from the PTSD group, $p=0.14$, or the healthy control group, $p=0.29$, in terms of educational level.

In the analyses reported in the main text we did not control for these differences as there is some evidence that differences in gender and educational level are dependent on the disorder (Brewin, Andrews, \& Valentine, 2000; Furmark et al., 1999; McLean, Asnaani, Litz, \& Hofmann, 2011), whereas the statistical age difference is unlikely to be meaningful for the outcome measures as the group means of age indicated that all participants were in a similar phase of their lives (e.g., Penningroth \& Scott, 2012; Rathbone \& Steel, 2015). Controlling for demographic variables could therefore be statistically problematic as their variation may be non-randomly linked to the independent group variable (Miller \& Chapman, 2001). However, a series of analyses were conducted co-varying for the demographic variables to investigate

\footnotetext{
2 The coding manual (in Dutch) can be requested from the corresponding author.
} 
Table 1

Means and standard deviations for all measures per group.

\begin{tabular}{|c|c|c|c|c|c|c|}
\hline & \multicolumn{2}{|c|}{$\operatorname{PTSD}(n=21)$} & \multicolumn{2}{|c|}{ Social Anxiety Disorder $(n=21)$} & \multicolumn{2}{|c|}{ Healthy controls $(n=21)$} \\
\hline & $M$ & $S D$ & $M$ & $S D$ & $M$ & $S D$ \\
\hline \multicolumn{7}{|l|}{ Demographic variables } \\
\hline Education & 2.90 & 1.79 & 3.71 & 1.93 & 4.29 & 1.49 \\
\hline Age & 39.29 & 12.31 & 32.38 & 8.82 & 32.67 & 9.82 \\
\hline \multicolumn{7}{|l|}{ Clinical scores } \\
\hline PSS-SR total score & 30.24 & 7.12 & 9.81 & 9.45 & 2.00 & 3.07 \\
\hline PSS-SR re-experiencing & 9.90 & 3.53 & 1.67 & 2.89 & 0.43 & 1.33 \\
\hline PSS-SR avoidance & 11.10 & 3.58 & 3.67 & 4.55 & 0.62 & 1.50 \\
\hline PSS-SR arousal & 9.24 & 2.21 & 4.48 & 3.22 & 0.95 & 0.92 \\
\hline BDI-II & 25.71 & 7.84 & 13.57 & 7.95 & 3.14 & 2.78 \\
\hline LSAS total score & 59.90 & 30.79 & 60.24 & 26.50 & 14.67 & 9.47 \\
\hline LSAS fear & 32.52 & 15.08 & 32.76 & 13.28 & 7.67 & 4.56 \\
\hline LSAS avoidance & 27.38 & 16.27 & 27.48 & 13.91 & 7.00 & 6.01 \\
\hline \multicolumn{7}{|l|}{ AMT selective recall } \\
\hline Number of trauma memories & 3.48 & 2.93 & 0.19 & 0.51 & 0.10 & 0.36 \\
\hline Number of social anxiety-related memories & 0.81 & 1.50 & 4.29 & 1.82 & 1.38 & 1.24 \\
\hline \multicolumn{7}{|l|}{ Self-defining memories } \\
\hline Number of trauma-related self-defining memories & 3.05 & 1.47 & 0.76 & 1.18 & 0.67 & 0.97 \\
\hline Number of social anxiety-related self-defining memories & 0.76 & 1.00 & 2.48 & 1.44 & 0.48 & 0.87 \\
\hline \multicolumn{7}{|l|}{ Goals } \\
\hline Number of trauma-related goals & 2.52 & 2.42 & - & - & - & - \\
\hline Number of social anxiety-related goals & 1.43 & 1.33 & 3.52 & 1.97 & 0.71 & 0.85 \\
\hline \multicolumn{7}{|l|}{ Self-views } \\
\hline Number of trauma-related self-views & 1.05 & 1.80 & - & - & - & - \\
\hline Number of social anxiety-related self-views & 0.62 & 0.67 & 2.14 & 1.68 & 0.14 & 0.48 \\
\hline \multicolumn{7}{|l|}{ Self-discrepancy } \\
\hline Ideal-actual self-discrepancy & 6.67 & 2.94 & 8.48 & 3.46 & 5.14 & 1.91 \\
\hline Ought-actual self-discrepancy & 6.57 & 3.01 & 7.67 & 3.68 & 4.62 & 1.80 \\
\hline
\end{tabular}

\section{Table 2}

Examples of AMT memories, self-defining memories, future goals, and self-views for the categories trauma-related, social anxiety-related, and neither (note: some details have been changed to ensure anonymity of the participants).

\begin{tabular}{|c|c|c|c|}
\hline & $\begin{array}{l}\text { Trauma- } \\
\text { related }\end{array}$ & $\begin{array}{l}\text { Social anxiety- } \\
\text { related }\end{array}$ & Neither \\
\hline $\begin{array}{l}\text { AMT } \\
\text { memories }\end{array}$ & $\begin{array}{l}\text { 'The day I lost } \\
\text { my virginity, } \\
\text { that I felt } \\
\text { special } \\
\text { because of my } \\
\text { sex abuse.' }\end{array}$ & $\begin{array}{l}\text { 'The day I had to } \\
\text { call that } \\
\text { customer. I was } \\
\text { very tense. I } \\
\text { have a slight fear } \\
\text { of telephoning.' }\end{array}$ & $\begin{array}{l}\text { 'Last week I had } \\
\text { my graduation. } \\
\text { Nice things were } \\
\text { said about me } \\
\text { there. All my } \\
\text { friends and } \\
\text { family were } \\
\text { there. It was a } \\
\text { nice day.' }\end{array}$ \\
\hline $\begin{array}{l}\text { Self- } \\
\text { defining } \\
\text { memories }\end{array}$ & $\begin{array}{l}\text { 'The moment I } \\
\text { ran away from } \\
\text { my ex. I stand } \\
\text { up for myself } \\
\text { more now. I } \\
\text { really } \\
\text { committed to a } \\
\text { path to work } \\
\text { on myself and } \\
\text { get my life } \\
\text { back on track.' }\end{array}$ & $\begin{array}{l}\text { 'When my aunt, } \\
\text { who is a } \\
\text { photographer, } \\
\text { wanted my sister } \\
\text { to pose for a } \\
\text { picture but not } \\
\text { me. I felt so } \\
\text { inferior.' }\end{array}$ & $\begin{array}{l}\text { 'I remember } \\
\text { playing with } \\
\text { Lego on the first } \\
\text { day of } \\
\text { kindergarten. } \\
\text { This shows that I } \\
\text { am an analytical } \\
\text { person and that I } \\
\text { like puzzles.' }\end{array}$ \\
\hline $\begin{array}{l}\text { Future } \\
\text { goals }\end{array}$ & $\begin{array}{l}\text { 'To have less } \\
\text { stress from my } \\
\text { trauma' }\end{array}$ & $\begin{array}{l}\text { 'To be more } \\
\text { assertive' }\end{array}$ & 'Being happy' \\
\hline Self-views & 'I am broken' & 'I am boring' & 'I am loyal' \\
\hline
\end{tabular}

Table 3

Inter-rater agreements (kappa) for the content coding of the responses on the AMT, self-defining memories, current goals, and self-views.

\begin{tabular}{lll}
\hline & Kappa $(\kappa)$ & $p$-value \\
\hline AMT & 0.67 & $<0.001$ \\
Self-defining memories & 0.63 & $<0.001$ \\
Current goals & 0.78 & $<0.001$ \\
Self-views & 0.79 & $<0.001$ \\
\hline
\end{tabular}


whether these had a significant impact on the outcome measures. The results remained overall similar. ${ }^{3}$

\subsection{Group verification}

In addition to the MINI, scores on the psychopathology questionnaires confirmed group membership. The PTSD group reported significantly more re-experiencing, avoidance, and arousal on the PSS-SR than the other two groups, all $p<0.001$. Avoidance and arousal (but not re-experiencing) scores were higher in the SAD group than the healthy control group, both $p<0.01$. LSAS scores were comparable among the SAD and PTSD group, $p=0.96$, and higher than in the healthy control group, both $p<0.001$. However, when controlling for PSS-SR scores, the SAD group reported significantly more social anxiety on the LSAS than the PTSD as well as the healthy control group, both $p<0.001$. Thus, the elevated LSAS scores in the PTSD group were explained by their PTSD symptoms. As would be expected, levels of depression were highest in the PTSD group, followed by the SA group, and lowest in the healthy control group, with significant differences between all groups, all $p<0.001$.

\subsection{AMT.}

There was a significant group difference in the number of trauma-related memories that were recalled on the AMT, $F(2,60)=26.19$, $p<0.001$. The PTSD group reported more trauma-related memories than the SAD and healthy control group, both $p<0.001$, both $d>1.91$, lowest $95 \%$ CI $[2.22,4.35]$, with no significant difference between the SAD and healthy control group, $p=0.86$. Similarly, there was a significant group difference in the number of social anxiety-related memories on the AMT, $F(2,60)=30.73, p<0.001$. The SAD group reported significantly more social anxiety-related memories than both the PTSD and healthy control group, both $p<0.001$, both $d>1.90$, lowest $95 \%$ CI $[1.95,3.86]$, with no significant difference between the PTSD and healthy control group, $p=0.23$. To test whether selective recall was stronger in either clinical group, the number of trauma memories in the PTSD group was compared to the number of social anxiety-related memories in the SAD group. This difference was not significant, corrected $t(33.47)=1.08, p=0.29$.

\subsection{Self-defining memories}

There was a significant group difference in the number of trauma-related self-defining memories, $F(2,60)=25.60, p=0.001$. The PTSD

\footnotetext{
3 The demographic variables (age, gender, and educational level) were non-significant covariates for the following outcome measures: trauma memories on the AMT (all $p>0.30$ ), social anxiety-related memories on the AMT (all $p>0.37$ ), disorder-congruent memories on the AMT (all $p>0.31$ ), trauma-related self-defining memories (all $p>0.07$ ), social anxiety-related self-defining memories (all $p>0.18$ ), disorder-congruent self-defining memories (all $p>0.44$ ), trauma-related goals (all $p>0.17$ ), social anxiety-related goals (all $p>0.10$ ), social anxiety-related self-views (all $p>0.13$ ). Age was a significant covariate for the effect of group on disorder-congruent future goals $(p=0.049)$. The group effect became significant, $F(1,37)=6.31, p=0.02$, with a higher number of disorder-related goals in the SAD group than the PTSD group. Age and educational level were significant covariates for the group effect on disorder-congruent self-views ( $p=0.003$ and $p=0.009$, respectively). The group effect became significant, $F(1,37)=13.27, p<0.001$, with a higher number of disorder-related self-views in the SAD group than the PTSD group. Adding the demographic variables in a separate block (first step) in the regression analysis did not significantly change the outcome of the final models of prediction of the trauma memories on the AMT (trauma-related future goals: $\beta=0.29, p=0.02$ ) and trauma-related self-defining memories (n.s.). The predictive value of social anxiety-related self-views in the prediction of social anxiety-related memories on the AMT became marginally significant $(\beta=0.26, p=0.07$ ), and remained significant for social anxiety-related self-defining memories $(\beta=0.29, p=0.01)$.
}

group reported significantly more trauma-related self-defining memories than the SAD group and the healthy control group, both $p<0.01$, both $d>0.72$, lowest $95 \%$ CI $[1.53,3.04]$, with no significant difference between the SAD and healthy control group, $p=0.80$. There was also a significant group difference in the number of social anxiety-related self-defining memories, $F(2,60)=19.33, p<0.001$. The SAD group reported significantly more social anxiety-related self-defining memories than the PTSD and healthy control group, both $p<0.001$, both $d>1.40$, lowest $95 \%$ CI $[1.02,2.41]$, with no significant difference between the PTSD and healthy control group, $p=0.42$. To test whether selective recall was stronger in either clinical group, the number of trauma-related self-defining memories in the PTSD group was compared to the number of social anxiety-related self-defining memories in the SAD group. There was no significant difference, $t(40)=1.28$, $p=0.21$, indicating that this temporal alteration regarding the past was comparable among these disorders.

\subsection{Future goals}

Trauma-related goals were exclusively reported in the PTSD group. There was a significant group difference in the number of social anxiety-related goals, $F(2,60)=21.21, p<0.001$. The SAD group reported more social anxiety-related goals than the PTSD and healthy control group, both $p<0.001$, both $d>1.26$, lowest 95\% CI [1.20, 2.99], with no significant difference between the PTSD and healthy control group, $p=0.12$. There was no significant difference in the number of trauma-related goals in the PTSD group and the number of social anxiety-related goals in the SAD group, $t(40)=1.47, p=0.15$, indicating that this temporal alteration regarding the future was comparable among these disorders.

\subsection{Self-views}

Trauma-related self-views were only reported in the PTSD group. There was a significant group difference in the number of social anxiety-related self-views, $F(2,60)=19.62, p<0.001$. The SAD group reported significantly more social anxiety-related self-views than the PTSD and healthy control group, both $p<0.001$, both $d>1.29$, lowest 95\% CI [0.86, 2.19], with no significant difference between the PTSD and healthy control group, $p=0.16 .{ }^{4}$ The number of social anxiety-related self-views in the SAD group was significantly higher than the number of trauma-related self-views in the PTSD group, $t(40)=2.04$, $p<0.05, d=0.63,95 \%$ CI $[0.01,2.18]$, indicating that this temporal alteration regarding self-processing in the present was comparable among these disorders.

\subsection{Predictors of trauma-related and social anxiety-related autobiographical recall}

Hierarchical regression analyses were conducted to test which components of self-processing (disorder-congruent future goals and present self-views, and self-discrepancies) predicted trauma-related recall and social anxiety-related autobiographical recall, whilst controlling for psychopathology symptoms. The analyses were conducted across the entire sample and not for the clinical groups separately (see also Krans et al., 2013; Sutherland \& Bryant, 2008). See Table 4 for the design and results of the regression analyses in more detail.

\footnotetext{
4 Using non-parametric tests, the number of social anxiety-related self-images is significantly higher in the PTSD group than the healthy control group, $p<0.01$.
} 
Table 4

Results of the hierarchical regression analyses for the prediction of trauma-related and social anxiety-related memories on the AMT and self-defining memories.

\begin{tabular}{|c|c|c|c|c|c|c|c|}
\hline \multicolumn{8}{|l|}{ Trauma-related recall on the AMT } \\
\hline Predictors & $\Delta R^{2}$ & df & $F$ change & $\mathrm{B}$ & SE & $\beta$ & $t$ \\
\hline 1. & 0.46 & 4,58 & $12.36^{* *}$ & & & & \\
\hline PSS-SR re-experiencing & & & & 0.31 & 0.08 & 0.67 & $3.68^{\text {** }}$ \\
\hline PSS-SR avoidance & & & & -0.09 & 0.09 & -0.21 & -0.91 \\
\hline PSS-SR arousal & & & & -0.01 & 0.13 & -0.02 & -0.07 \\
\hline BDI-II & & & & 0.05 & 0.05 & 0.23 & 0.97 \\
\hline 2. & $<0.01$ & 2,56 & 0.11 & & & & \\
\hline Ideal-Actual self-discrepancy & & & & 0.04 & 0.10 & 0.06 & 0.43 \\
\hline Ought-Actual self-discrepancy & & & & -0.01 & 0.10 & -0.02 & -0.11 \\
\hline 3. & 0.08 & 2,54 & $4.83^{*}$ & & & & \\
\hline Trauma-related goals & & & & 0.37 & 0.16 & 0.29 & $2.34^{*}$ \\
\hline Trauma-related self-views & & & & 0.27 & 0.23 & 0.13 & 1.19 \\
\hline \multicolumn{8}{|c|}{ Trauma-related self-defining memories } \\
\hline Predictors & $\Delta R^{2}$ & $\mathrm{df}$ & $F$ change & B & SE & $\beta$ & $t$ \\
\hline 1. & 0.39 & 4,58 & $9.13^{* * *}$ & & & & \\
\hline PSS-SR re-experiencing & & & & 0.16 & 0.06 & 0.49 & $2.55^{*}$ \\
\hline PSS-SR avoidance & & & & -0.08 & 0.07 & -0.27 & -1.09 \\
\hline PSS-SR arousal & & & & 0.09 & 0.10 & 0.23 & 0.93 \\
\hline BDI-II & & & & 0.03 & 0.04 & 0.18 & 0.70 \\
\hline 2. & 0.05 & 2,56 & $2.71^{+}$ & & & & \\
\hline Ideal-Actual self-discrepancy & & & & -0.13 & 0.07 & -0.26 & $-1.19^{+}$ \\
\hline Ought-Actual self-discrepancy & & & & 0.01 & 0.07 & 0.01 & 0.08 \\
\hline 3. & 0.04 & 2,54 & 2.20 & & & & \\
\hline Trauma-related goals & & & & 0.12 & 0.12 & 0.13 & 1.01 \\
\hline Trauma-related self-views & & & & 0.24 & 0.17 & 0.17 & 1.42 \\
\hline \multicolumn{8}{|c|}{ Social anxiety-related recall on the AMT } \\
\hline Predictors & $\Delta R^{2}$ & df & $F$ change & B & SE & $\beta$ & $t$ \\
\hline 1. & 0.25 & 3,59 & $6.54^{* * *}$ & & & & \\
\hline LSAS fear & & & & 0.09 & 0.04 & 0.69 & $2.08^{*}$ \\
\hline LSAS avoidance & & & & 0.01 & 0.04 & 0.04 & 0.12 \\
\hline BDI-II & & & & -0.13 & 0.03 & -0.66 & $-3.91^{* *}$ \\
\hline 2. & 0.04 & 2,57 & 1.42 & & & & \\
\hline Ideal-Actual self-discrepancy & & & & $<0.01$ & 0.11 & -0.01 & -0.03 \\
\hline Ought-Actual self-discrepancy & & & & 0.14 & 0.11 & 0.21 & 1.36 \\
\hline 3. & 0.10 & 2,55 & $4.54^{*}$ & & & & \\
\hline Social anxiety-related goals & & & & 0.21 & 0.16 & 0.18 & 1.27 \\
\hline Social anxiety-related self-views & & & & 0.48 & 0.22 & 0.31 & $2.22^{*}$ \\
\hline \multicolumn{8}{|c|}{ Social anxiety-related self-defining memories } \\
\hline Predictors & $\Delta R^{2}$ & df & $F$ change & B & SE & $\beta$ & $t$ \\
\hline 1. & 0.47 & 3,59 & $17.13^{\text {** }}$ & & & & \\
\hline LSAS fear & & & & 0.12 & 0.02 & 1.39 & $4.99^{* * *}$ \\
\hline LSAS avoidance & & & & -0.04 & 0.02 & -0.46 & $-1.73^{+}$ \\
\hline BDI-II & & & & -0.08 & 0.02 & -0.63 & $-4.41^{* * *}$ \\
\hline 2. & 0.09 & 2,57 & $5.86^{* *}$ & & & & \\
\hline Ideal-Actual self-discrepancy & & & & 0.12 & 0.06 & 0.27 & $2.22^{*}$ \\
\hline Ought-Actual self-discrepancy & & & & 0.04 & 0.06 & 0.09 & 0.72 \\
\hline 3. & 0.06 & 2,55 & $4.13^{*}$ & & & & \\
\hline Social anxiety-related goals & & & & 0.06 & 0.09 & 0.08 & 0.74 \\
\hline Social anxiety-related self-views & & & & 0.28 & 0.11 & 0.27 & $2.42^{*}$ \\
\hline
\end{tabular}

$+p<0.10$

$* p<0.05$.

** $p<0.01$.

\subsubsection{Trauma-related recall on the AMT}

A three step hierarchical regression analysis showed that the first model, including the PSS-SR subscales and the BDI-II, explained 46\% of variation in trauma-related recall on the AMT. The re-experiencing subscale of the PSS-SR was the only significant predictor. The self-discrepancies did not significantly add to the prediction in the second model. Adding trauma-related goals and self-views in the third model added another $8 \%$ uniquely explained variance. The number of trauma-related goals were the only significant predictor.

\subsubsection{Trauma-related recall in self-defining memories}

A similar regression analysis was performed but with the number of trauma-related self-defining memories as the dependent variable. 
Again, the first model with the PSS-SR subscales and the BDI-II explained a significant $39 \%$ of variance. This was only due to re-experiencing symptoms on the PSS-SR. Adding self-discrepancies in the second model, and trauma-related goals and self-views in the third model did not significantly add to the prediction.

\subsubsection{Social anxiety-related recall on the AMT}

A three step hierarchical regression showed that the first model, including the LSAS subscales and the BDI-II, explained a significant $25 \%$ of variation in social-anxiety related recall on the AMT. The LSAS fear subscale and BDI-II were significant predictors. Self-discrepancies in the second model did not explain any additional variance. The third model added another $10 \%$ in uniquely predicted variance. The number of social anxiety-related self-views was the only significant predictor.

\subsubsection{Social anxiety-related recall in self-defining memories}

A similar regression analysis was performed but with the number of social anxiety-related self-defining memories as the dependent variable. LSAS subscales and the BDI-II in the first model explained a significant $47 \%$ of the variance. This was due to the LSAS fear subscale and BDI-II scores. Adding the self-discrepancy scores in the second model added another $9 \%$ of uniquely explained variance, with Ideal-Actual self-discrepancy as only significant predictor. The third model added another $6 \%$ of uniquely explained variance. The number of social anxiety-related self-views was the only significant predictor.

\section{Discussion and conclusions}

The results of the current study showed that disorder-congruent autobiographical recall was found in both PTSD and SAD. This aligns with previous findings from Sutherland and Bryant $(2005,2008)$ who showed that PTSD patients recall more trauma-related memories in response to cue words and more trauma-related self-defining memories compared to traumatized controls without PTSD. It also aligns with the finding of Krans et al. (2013) of higher recall of social anxiety-related memories in a high socially anxious group of university students, and extents these findings to a clinical SAD population. This selective recall, which was also predicted by cognitive models of PTSD (e.g., Ehlers \& Clark, 2000) and SAD (Clark \& Wells, 1995; Gregory et al., 2017; Heimberg et al., 2010; Hofmann, 2007; Moscovitch, 2009), thus appears to be a reliable finding. Moreover, disorder-congruent temporal alterations were also found for self-processing in the present and the future, as reflected by the presence of disorder-congruent current self-views and future goals. This suggests that the conceptualization of the self across time as proposed by the Sense of Self framework (Prebble et al., 2013) and dimensions of self according to Stopa (2009) are also a relevant and useful framework to better understand PTSD and SAD. In regard to the first aim of this study, and in alignment with our predictions, we can conclude that disorder-congruent temporal alterations in self-processes stretch across representations of the self in the past, present, and future in both PTSD and SAD.

Furthermore, there were no significant differences in the number of disorder-congruent autobiographical memories, current self-views, or future goals between PTSD and SAD participants. ${ }^{5}$ Thus, in response to the second aim of our study, and in line with predictions, we can conclude that temporal alterations (or biases) in self-processing emerge to a similar extent in PTSD and SAD patients. This could indicate that disorder-congruent self-processing is a transdiagnostic phenomenon, although further studies in different clinical populations are required to

\footnotetext{
5 Except when demographic variables were controlled for, in which case the number of disorder-congruent future goals and self-views were significantly higher in the SAD group.
}

confirm this. It is possible that these temporal alterations are limited to PTSD, SAD, anxiety disorders, or they could be related to trauma to the extent to which SAD patients also show a history of trauma. Future studies should therefore include a measure of trauma history, and include other clinical groups to investigate this transdiagnostic question further.

As disorder-congruent autobiographical recall has been proposed as an important mechanism in the maintenance of PTSD and SAD, the contribution in its prediction of present and future self-processing was analyzed according to the third aim of this study. The hierarchical regression analyses showed that trauma-related recall on the AMT, when controlling for PTSD symptoms and depressive symptoms, was predicted by the presence of future goals related to trauma, but not by trauma-related self-views. This outcome was somewhat different than expected. That is, the SMS model (Conway \& Pleydell-Pearce, 2000; Conway, 2005) proposed that the working self, which consists of both current self-views and future goals, guides autobiographical recall in a bi-directional relation. However, our data suggests that the future goals of the working self are more influential than current self-views in accessing trauma-related memories. This may be surprising given that the concept of event centrality posits that a highly central traumatic event impacts directly on one's identity (Berntsen \& Rubin, 2006, 2007; Rubin et al., 2008). On the other hand, a sense of foreshortened future has been acknowledged in PTSD as well (e.g., Ehlers \& Clark, 2000). Our results indicate that projecting the traumatized self into the future is associated with higher accessibility of trauma-related memories, which maintains the disorder. Clinically, this would imply that effective therapy would not necessarily solely focus on how the trauma impacted current self-views, but also on creating or re-building a strong future self.

Conversely, addressing intrusive memories of trauma (e.g., with imaginal exposure techniques) could in turn affect future projections. Imagery rescripting (e.g., Arntz, 2012) is another technique that is showing promising clinical results (e.g., Arntz, Tiesema, \& Kindt, 2007). Here, the trauma memory is altered using mental imagery, which is proposed to impact on views of the self as having a sense of control or mastery. It would be interesting for future studies to test whether using mental imagery for future projections of the self could be equally effective, which may be less distressing than addressing the trauma memory directly. However, our finding that trauma-related recall is associated with future projections of the self rather than current self-views requires replication to test its reliability, and experimental studies are necessary to test causality of these relations. Furthermore, self-processing did not appear to predict the recall of trauma-related memories. Perhaps this can be explained in light of the reasoning above: self-defining memories are per definition about memories related to current self-identity, whereas the AMT assessed memory accessibility. As current self may not be predictive of accessibility of trauma memories (as suggested by the AMT findings), this could explain the lack of predictive value of these factors in self-defining memories. However, our findings is not in line with that of Sutherland and Bryant (2005) where personal trauma-related goals were predictive of trauma-related self-defining memories, and self-discrepancy predicted trauma-related recall in response to (the same) cue words. In regard to the latter study, possible methodological differences in assessing self-discrepancy may explain this difference. There do not appear to be obvious methodological differences with the 2008 study, however, but it is possible that there were differences in coding schemes because the current study also included an SAD group which may have affected the interpretation of reported self-defining memories or goals. Replication studies are needed to clarify these differences.

Social anxiety-related memories were predicted by current self-views but not future goals. The role of the self has indeed been emphasized by models of SAD (e.g., Gregory et al., 2017). The finding also 
aligns with those reported by Krans et al. (2013), where future goals did not predict autobiographical recall of socially feared situations in high socially anxious students. The current study extends these findings to a clinical population, and by showing that current disorder-congruent self-views predict social anxiety-related autobiographical recall. These findings were found for both the AMT and self-defining memories. That suggests that current self-representations are associated with both the accessibility of congruent memories as well as the extent to which such memories are connected to self-identity. For self-defining memories, a discrepancy between the ideal self and current self was also significant, which aligns with models of SAD (e.g., Hofmann, 2007). In this sense, it appears that SAD is a disorder which is more associated with a dysfunctional present self, rather than dysfunctional future projections of the self (see also Moscovitch, 2009). Clinical implications are that it would be helpful to alter explicit current self-views rather than focusing on ideas about who the patients believes s/he ought to be or ideally would like to be, or how they see themselves in the future. Again, because this study was correlational in nature, the reverse could also be true (e.g., addressing past memories could alter current self-views). To test the direction and causality of this relation experimental studies are required.

The present study has several limitations. First, there were differences in demographic variables between the PTSD group and the other two groups. These were to be expected based on what is known about these disorders. For example, more women than men develop PTSD, but this gender difference is absent for SAD (McLean et al., 2011), and whereas low educational level has indeed been identified as a risk factor for PTSD (Brewin et al., 2000), SAD has conversely been identified as a risk factor for low educational attainment due to shyness (Furmark et al., 1999). Finally, although the age differences were marginally statistically significant, all groups on average were in a similar life phase (in their thirties), which makes it unlikely that this small difference would have any meaningful effect on the memory bias, future goals, or self-views (e.g., Penningroth \& Scott, 2012; Rathbone \& Steel, 2015). Thus, there appear to be no theoretical reasons to assume any relevant effect of these demographic differences in our sample. Second, the groups differed in levels of depression, with the PTSD group reporting the highest BDI-II scores. This was also unsurprising given that depressive symptoms are common in people with psychological disorders and especially PTSD (Moore \& Zoellner, 2007; Williams et al., 2007). Depression was statistically controlled for in the regression analyses therefore the results cannot be ascribed to these differences. However, the current diagnostic criteria for PTSD and depression show significant overlap, which makes the confound between PTSD and depression also a broader issue to do with our current diagnostic practices. Indeed, studies have shown that, for example, depressive patients without PTSD and PTSD patients without depression consistently score comparably on PTSD symptoms subscales (Gros, Price, Magruder, \& Frueh, 2012). Depressive symptoms are thus part of reality for people with PTSD and other types of psychopathology due to comorbidity, and completely isolating any effects of depression would also affect ecological validity.

Overall, the findings align with the SMS model (Conway, 2005; Conway \& Pleydell-Pearce, 2000), in that alterations in self-processing on a temporal dimension were supported in the PTSD and SAD samples. Furthermore, it appeared that different components of the working self were important in disorder-congruent recall in PTSD (future goals) and SAD (current self-views). This would not necessarily be predicted by the SMS model and shows that there are disorder-specific processes that are perhaps better explained by more clinically oriented models of PTSD and SAD (cf. supra). Moreover, most effect sizes were large, indicating strong effects, which supports the importance of temporal self-processing of these disorders. Pending replication and experimental tests of causality, clinical implications could be that, in order to reduce disorder-congruent autobiographical recall, attention should be paid to future goals in PTSD (e.g., modifying unrealistic or abstract trauma-related goals, promoting healthy and positive goals) and current self-views in SAD (e.g., using cognitive techniques, behavioral experiments, or rescripting techniques to modify current self-views).

\section{Acknowledgements}

We are grateful to all participants who made this research possible. This research did not receive any specific grant from funding agencies in the public, commercial, or not-for-profit sectors. This project was organized within the collaborative network of $\mathrm{NijCa}^{2} \mathrm{re}$ (www.nijcare.nl).

\section{References}

Arntz, A., Tiesema, M., Kindt, M., 2007. Treatment of PTSD: A comparison of imaginal exposure with and without imagery rescripting. Journal of Behavior Therapy and Experimental Psychiatry 38, 345-370.

Arntz, A., 2012. Imagery rescripting as a therapeutic technique: Review of clinical trials, basic studies, and research agenda. Journal of Experimental Psychopathology 3, 189-208.

Beck, A.T., Steer, R.A., Brown, G.K., 1996. Manual for the Beck Depression Inventory-II. Psychological Corporation, San Antonio, TX

Beck, A.T., 1976. Cognitive therapy and the emotional disorders. International Universities Press, New York.

Berntsen, D., Rubin, D.C., 2006. The centrality of event scale: A measure of integrating trauma into one's identity and its relation to post-traumatic stress disorder symptoms. Behaviour Research and Therapy 44, 219-231.

Berntsen, D., Rubin, D.C., 2007. When a trauma becomes a key to identity: Enhanced integration of trauma memories predicts posttraumatic stress disorder symptoms. Applied Cognitive Psychology 21, 417-431.

Brewin, C.R., Andrews, B., Valentine, J.D., 2000. Meta-analysis of risk factors for Posttraumatic Stress Disorder in trauma-exposed adults. Journal of Consulting and Clinical Psychology 68, 748-766.

Clark, D.M., Wells, A., 1995. A cognitive model of social phobia. In: Heimberg, R.G., Liebowitz, M., Hope, D.A., Schneider, F.R. (Eds.), Social phobia: Diagnosis, assessment, and treatment. Guilford Press, New York, NY, pp. 69-92.

Cohen, J., 1988. Statistical power analysis for the behavioral sciences, 2nd. ed. Lawrence Earlbaum Associates., Hillsdale, NJ.

Conway, M.A., Pleydell-Pearce, C.W., 2000. The construction of autobiographical memories in the Self-Memory System. Psychological Review 107, [621-288]

Conway, M.A., 2005. Memory and the self. Journal of Memory and Language 53, 594-628. Craske

and

Mys-

tkowski,

2006 Craske M.G., Mystkowski J.L., Exposure therapy and extinction: Clinical studies, in: Craske M.G., Hermans D., Vansteenwegen D. (Eds.), Fear and Learning: From Basic Processes to Clinical Implications, American Psychiatric Association, Washington, DC, 2006, pp. 217-233.

Cuthbert, B.N., Insel, T.R., 2013. Toward the future of psychiatric diagnosis: The seven pillars of RDoC. BMC Medicine 11, 126.

Damasio, A., 2003. Mental self: The person within. Nature 423, 227.

Dozois, D.J.A., Dobson, K.S., Ahnberg, J.L., 1998. A psychometric evaluation of the Beck Depression Inventory-II. Psychological Assessment 10, 83-89.

Ehlers, A., Clark, D.M., 2000. A cognitive model of posttraumatic stress disorder. Behaviour Research and Therapy 38, 319-345.

Emmons, R.A., 1986. Personal strivings: An approach to personality and subjective well-being. Journal of Personality and Social Psychology 51, 1058-1068.

Fivush, R., Haden, C.A., Reese, E., 2006. Elaborating on elaborations: Role of maternal reminiscing style in cognitive and socioemotional development. Child Development 77, 1568-1588.

Foa, E.B., Riggs, D.S., Dancu, C.V., Rothbaum, B.O., 1993. Reliability and validity of a brief instrument or assessing Post-Traumatic Stress Disorder. Journal of Traumatic Stress 6 , 459-473.

Furmark, T., Tillfors, M., Everz, P.-O., Marteinsdottir, I., Gefvert, O., Fredrikson, M., 1999. Social psychiatry and psychiatric epidemiology $34,416-424$

Gregory, B., Peters, L., Rapee, R.M., 2017. The self in social anxiety. In: Kyrios, M., Mould ing, R., Nedeljkovic, M., Bhar, S.S., Doron, G., Mikulincer, M. (Eds.), The Self in Psychological Disorders. Cambridge University Press, Cambridge, UK, pp. 91-101.

Gros, D.F., Price, M., Magruder, K.M., Frueh, B.C., 2012. Symptom overlap in posttraumatic stress disorder and major depression. Psychiatry Research 196, 267-270.

Harré, R., 1998. The singular self: An introduction to the psychology of personhood. Sage, London.

Heimberg, R.G., Horner, K.J., Juster, H.R., Safren, S.A., Brown, E.J., Schneier, F.R., et al., 1999. Psychometric properties of the Liebowitz Social Anxiety Scale. Psychological Medicine 29, 199-212. 
Heimberg, R.G., Brozovich, F.A., Rapee, R.M., 2010. A cognitive behavioral model of social anxiety disorder: Update and extension. In: Hofmann, S.G., Dibartolo, P.M. (Eds.), Social Anxiety: Clinical, Developmental, and Social Perspectives. Elsevier Academic Press, pp. 395-422.

Higgins, E.T., Shah, J., Friedman, R., 1997. Emotional responses to goal attainment: Strength of regulatory focus as a moderator. Journal of Personality and Social Psychology 72, 515-525.

Hofmann, S.G., 2007. Cognitive factors that maintain social anxiety disorder: A comprehensive model and its treatment implications. Cognitive Behaviour Therapy 36, 193-209.

Holmes, E.A., Lang, T.J., Shah, D.M., 2009. Developing interpretation bias modification as a cognitive vaccine for depressed mood: Imagining positive events makes you feel better than thinking about them verbally. Journal of Abnormal Psychology 118, 76-88.

Horton, C.R., Moulin, C.J.A., Conway, M.A., 2009. The self and dreams during a period of transitions. Consciousness and Cognition 18, 710-717.

Inquisit 4.0.9.0, 2015. Computer software. Millisecond Software LLC, Seattle, WA.

James, W., 1890. The principles of psychology. Henry Holt \& Co., American Science Series, New York.

Kazdin, A.E., 2007. Mediators and mechanisms of change in psychotherapy research. Annual Review of Clinical Psychology 3, 1-27.

Krans, J., De Bree, J., Bryant, R.A., 2013. Autobiographical memory bias in social anxiety. Memory 22, 890-897.

Kuhn, M.H., McPartland, T.S., 1954. An empirical investigation of self-attitudes. American Sociological Review 19, 68-76.

Landis, J.R., Koch, G.G., 1977. The measurement of observer agreement for categorical data. Biometrics 33, 159-174.

Liebowitz, M.R., 1987. Social phobia. Modern Problems in Pharmacopsychiatry 22, 141-173.

Mayo-Wilson, E., Dias, S., Mavranezouli, I., Kew, K., Clark, D.M., Ades, A.E., et al., 2014. Psychological and pharmalogical interventions for social anxiety disorder in adults: A systematic review and network meta-analysis. The Lancet Psychiatry 1, 368-376.

McAdams, D.P., 1993. The stories we live by: Personal myths and the making of the self. Guilford Press.

McLean, C.P., Asnaani, A., Litz, B.T., Hofmann, S.G., 2011. Gender differences in anxiety disorders: Prevalence, course of illness, comorbidity, and burden of illness. Journal of Psychiatry Research 45, 1027-1035.

Miller, G.A., Chapman, J.P., 2001. Misunderstanding analysis of covariance. Journal of Abnormal Psychology 110, 40-48.
Moore, S.A., Zoellner, L.A., 2007. Overgeneral autobiographical memory and traumatic events: An evaluative review. Psychological Bulletin 133, 419-437.

Moscovitch, D.A., 2009. What is the core fear in social phobia? A new model to facilitate individualized case conceptualization and treatment. Cognitive and Behavioral Practice $16,123-134$.

Ng, A.S., Abbott, M.J., Hunt, C., 2014. The effect of self-imagery on symptoms and processes in social anxiety: A systematic review. Clinical Psychology Review 34, 620-633.

Overbeek, T., Schruers, K., \& Griez, E. (1997, 1999). Nederlandse vertaling MINI Neuropsychiatric Interview. University of Maastricht, the Netherlands.

Penningroth, S.L., Scott, W.D., 2012. Age-related differences in goals: Testing predictions from selection, optimization, and compensation theory and socioemotional selectivity theory. International Journal of Aging and Human Development 74, 87-111.

Prebble, S.C., Addis, D.R., Tippett, L.J., 2013. Autobiographical memory and sense of self. Psychological Bulletin 139, 815-840.

Rapee, R.M., Heimberg, R.G., 1997. A cognitive-behavioural model of anxiety in social phobia. Behaviour Research and Therapy 35, 741-756.

Rapee, R.M., Gaston, J.E., Abbott, M.J., 2009. Testing the efficacy of theoretically derived improvements in the treatment of social phobia. Journal of Consulting and Clinical Psychology 77, 317-327.

Rathbone, C., Steel, C., 2015. Autobiographical memory distributions for negative self-images: Memories are organised around negative as well as positive aspects of identity. Memory 23, 473-486.

Ross, M., Wilson, A.E., 2003. Autobiographical memory and conceptions of self getting better all the time. Current Directions in Psychological Science 12, 66-69.

Rubin, D.C., Berntsen, D., Bohni, M.K., 2008. A memory-based model of posttraumatic stress disorder: Evaluating basic assumptions underlying the PTSD diagnosis. Psychological Review 115, 985-1011.

Stopa, L., 2009. Reconceptualizing the self. Cognitive and Behavioral Practice 16, $142-148$.

Sutherland, K., Bryant, R.A., 2005. Self-defining memories in post-traumatic stress disorder. British Journal of Clinical Psychology 44, 591-598.

Sutherland, K., Bryant, R.A., 2008. Autobiographical memory and the self-memory system in posttraumatic stress disorder. Journal of Anxiety Disorders 22, 555-560.

Williams, J.M.G., Broadbent, K., 1986. Autobiographical memory in suicide attempters. Journal of Abnormal Psychology 95, 144-149.

Williams, J.M.G., Barnhofer, T., Crane, C., Hermans, D., Raes, F., Watkins, E., et al., 2007. Autobiographical memory specificity and emotional disorder. Psychological Bulletin $133,122-148$. 